\title{
The Collaborative Approach in Content and Language Integrated Learning
}

\author{
María Luisa Carrió Pastor and David Perry \\ Polytechnic University of Valencia \\ 1carrio@idm.upv.es / daper@idm.upv.es
}

\begin{abstract}
The specific knowledge that can be found in web sites provides a source of information which should be used by language teachers and content teachers to teach students both subject matter and language at the same time. In this paper, we describe the methodology followed in a still ongoing project in which content teachers and language teachers collaborated in order to design online teaching-learning materials which integrated subject matter and language tasks. We explain the criteria followed in designing and evaluating the different activities proposed in order to connect two subjects that have been traditionally taught separately and we provide some examples. Our main conclusion is that language teaching and content teaching can be successfully integrated. The activities proposed proved to be encouraging for both content learning and second language learning, reinforcing students' self-steem and collaborative behaviour in the classroom and online.
\end{abstract}

\section{Introduction}

There is no doubt that the introduction of computers has revolutionised second language (L2) teaching (Chapelle, 2001;2003; 2004; Richards, 2005). The possibilities afforded by the use of the Internet or by exploiting the information on the World Wide Web, including the chance to use real texts or to communicate with people around the world, have brought new concepts to teaching. Furthermore, the development of technology tools, whether specifically for language learning or not, has resulted in fundamental changes in classroom practices and brought with it new responsibilities for language teachers. 
Students' expectations have also changed. Students now value their teachers more if they are reasonably competent users of technology, and if they incorporate in effective and enjoyable ways computer-mediated activities in their teaching materials and classes (Lea, Clayton, Draude \& Barlow, 2001; Imus, Ployhart, Ritzer \& Sleigh, 2004; Schrodt \& Turman, 2005; Spodark, 2005; Li, 2006). Moreover, students have become accustomed to the ease and speed with which information can be accessed or messages transmitted and now expect online access to syllabus descriptions, assignments and materials for class work.

Although some students report negative experiences, most appear to be positive about the incorporation of technology in their classes (Taylor \& Hitsaki, 2004). The main advantages of using technology for language learning are because it facilitates greater exposure to authentic language, access to a wide range of sources of information and to different varieties of language, opportunities for interaction and communication and greater learner participation (Carrió Pastor, 2009a).

The rapid accessibility of information via the World Wide Web is now something we take for granted, and, as Luke (2006: 33 ) points out, as computers and related technologies steadily become an integral part of many societies and education systems " $[. .$.$] the possibilities for$ computer use in language learning settings are bounded only by the creativity and ingenuity of the designer or instructor." Nevertheless, this does not mean that technology should be used for its own sake. There have to be sound pedagogical reasons for using technology in language learning contexts, and this requires knowing what technology to use and a high level of skill in choosing and designing language learning tasks.

We should also bear in mind that the use of online materials does not necessarily involve engaging in a new form of teaching or learning. The tools technology provides may facilitate learning or be somehow more motivating. This happens because they enhance accessibility and immediacy to the processes of learning, although these processes may not, in fact, be different from those engaged in with paper-based materials. But technology does not per se involve the language student engaging different learning processes. We would argue, in fact, that the majority of learning activities employed in computer-based teaching are, for the most part, online versions of already existing activities with paper-based materials. To put it another way, unless the tools which technology provides are not used innovatively their use does not constitute, by itself, a groundbreaking new approach. The self-correction of exercises and online tutorials smooth the progress of language acquisition; nevertheless the tasks proposed in online materials are based on the same approaches than written material.

\section{The Collaborative Approach in Content and Language Integrated Learning}

Collaborative learning is a teaching approach which enhances maturity, experience and social communication in an academic environment while discouraging passivity, repetition and individuality. In collaborative learning, students can develop their own learning strategies and select their own objectives. At the same time they are responsible for what they learn and how they gain knowledge of a topic. Collaborative learning has long been of interest to practitioners of communicative language teaching since it offers widely tested classroom 
procedures such as those described, for example, by McCafferty, Jacobs and Dasilva Iddings (2006).

The interdependency and mutual respect between the components of the collaborative activity is essential to obtain a coherent proposal. Students and teachers should become a coherent group that dialogues and negotiates in a dynamic class (González Fernández, 2006: 3). Nunan (1991: 1) suggests a number of reasons for collaborating:

In language education, teachers, learners, researchers and curriculum specialists can collaborate for a number of reasons. They may wish to experiment with alternative ways of organizing teaching and learning; they may be concerned with promoting a philosophy of cooperation rather than competition; they may wish to create an environment in which learners, teachers and researchers are teaching and learning from each other in an equitable way [...]; or they may wish to experiment with ways of incorporating principles of learner-centredness into their programs.

Thus, there are different motivations for incorporating collaborative approaches and different ways in which such approaches can be implemented in language learning. In all of them, however, collaboration can be broadly understood as; “...the mutual engagement of participants in a coordinated effort to solve the problem together" (Roschelle \& Teasley, 1995: 70). Thus, the teacher is present to assist language learning while the students collaborate in elaborating tasks. Under teacher guidance, the students make connections between previous knowledge and new information. They use language and technology as tools for learning and develop language and thinking competences. Collaborative work should be well planned and teachers should design strategies that provide all the participants with clear roles in the different parts of the action research.

There are two modalities to consider in the collaborative approach. On the one hand, teachers from different areas of knowledge collaborate in order to offer learning tools to students. On the other hand, students work collaboratively in the classroom to carry out the tasks proposed by the teacher. In both modalities, the roles of the teachers and students are different. In the first one, the teacher is central to the learning activity, facilitating the interdisciplinary tasks to the passive students. The teacher's role is more facilitative; to guide and channel the students in their learning. In the second, the teacher's role is less active, helping the students but not interfering in the learning process. We propose a third modality which combines these two, in which teachers and students collaborate in the design and evaluation of the teaching-learning activities, thereby taking into account individual and group needs of the students (Carrió Pastor, 2006). Collaboration implies interaction among the different members of the group and the different proposals should act as webs of knowledge that combine to offer unique results (Strijbos, Martens and Jochems, 2004: 403).

Furthermore, would like to introduce here a further aspect. The Collaborative Approach (CA) combined with the Content and Language integrated Learning (CLIL) approach, which integrates the learning process of a second language and specific topics of content subjects (Carrió \& Gimeno, 2007 and Carrió Pastor, 2009b: 39). As the target language is the means of learning content, students tend to be highly motivated and language acquisition is integrated in the learning process. Content teachers and language teachers integrate their learning approaches in order to obtain a higher learning outcome from students. 
We believe that CLIL should be taught as a single subject being based on close cooperation between content teachers and language teachers. Some researchers into this approach (Wolf, 2007; Marsh, 2009; Coyle, 2007; 2009; Hodgson and Jones, 2009; Morton, 2009 and Ezeiza Ramos, 2009) consider that the role of the language teacher is merely that of 'assistant' to the content teacher. In our view, both content and language are of equal importance and both the content and language teachers collaborate to produce specific materials which allow different aspects to be focused on.

In addition, we start from the belief that collaborative learning implies interactive learning and we accept that technology can facilitate communication and make the learning process more effective. Online learning can generate a positive interdependency, can promote verbal exchange, can stimulate personal and group skills while giving due value to individual contributions. As such, it is ideally suited to collaborative and content-based activities: "The computer-as-a-tool agrees with the fact that today a number of educators are seeking ways to teach in more content-based approaches" (Soetaert \& Bonamie, 2006:5).

Our main aim in this research was to determine whether blending different approaches and incorporating the regular use of technology would result in appropriate materials for teaching second language learners in Higher Education. We present examples of specific materials which were designed by teachers and students working together. Finally, we aim to show that content teachers and language teachers should collaborate together in order to create materials for second language and content learning, and that this collaboration can result in new and innovative learning methodologies.

\section{Methodology}

There were several factors that led us to design material based on the possibilities provided by the Internet and combining the content and language integrated learning approach with the collaborative approach. The first was that we could easily contact content teachers from different engineering courses. The second was that there was a homogenous group of engineering students that could help us in our teaching project and research into the design of materials. Last but not least was that the adoption of the so-called Bologna process, and specifically gearing language courses to be compatible with The Common European Framework ${ }^{1}$, was forcing changes in second language teaching objectives and strategies.

The Internet could offer new learning possibilities, which would be well-suited to the current and future demands of society and students, but that new approaches were needed in order to design online materials which could make full use of the potential. Among the ideas discussed, the Content and Language Integrated Learning approach and the Collaborative approach were put forward as a way of stimulating students to learn both subject matter and English as a second language through the use of a versatile tool; namely, the Internet. The procedure to follow was discussed by all the members of the research group, in order to plan the different strategies and develop the materials using a sound methodology to obtain the best results. We followed the action research model described by Burns (1999), which takes into account factors such as: group discussion, role definitions and processes, constraints, finding 
a focus, collecting data, analysing the data, collaborative work in practice and evaluation of the results. In the following sections, this general procedure is explained in order to describe the qualitative research undertaken.

The project discussed in this paper was carried out at the Universidad Politécnica de Valencia. The principal aim was to create and pilot domain-specific English materials to students of Industrial Engineering. The materials would include both foreign language study material and subject matter study material. All the tasks would be based on specific web sites and the activities would be available online to students through a university intranet. The novelty here is that the materials would be created through collaboration between language teachers, content teachers and students.

The first part of the project focused on the selection of previously analysed web sites. This task was performed jointly by a group of engineering students and a group of content teachers who were, in turn, coordinated by the English language teachers. Students and content teachers chose the ten topics they felt would be most useful in the first year syllabus of the Industrial Engineering course. Reasons for choosing a topic included, for example, relevance, whether the subject provided a foundation for further topics later in the course, or interest level. Students were then divided into five groups with the task of selecting three web sites for each of the ten chosen topics. The following criteria were used to evaluate each site:

1. Reliability and regular updating of the contents of the web site.

2. Identification of the creator of the web site and/or its contents.

3. The stability of the web site (institutional or corporative were preferred).

4. Specific sections of the web site and its overall coherence (instructions).

5. Technical facilities for navigation through the different sections.

6. Lexicon adapted for the practice of a second language.

7. Interaction between the web site and its user.

The students then ranked the sites depending on the degree to which they satisfied the above criteria. The three web sites that obtained the highest ranking from the fifteen proposed were chosen for each of the ten topics. This gave us thirty web sites which would provide the basis for the teaching-learning materials. The web sites were grouped into content areas making it easier to recycle the practise and reinforcement of content specific vocabulary.

Once the web sites had been selected and approved, work began on the teaching-learning materials themselves. Discussions between content teachers and language teachers took into account the principles of collaboration, the available technology and CLIL. We divided each unit in different sections: introduction; objectives; online tasks; follow up and vocabulary. The reading material, included in the online tasks, was chosen from the web sites by the students following certain guidelines provided to them such as terminology, sentence complexity, or the place and/or importance of the topic in the syllabus.

Afterwards, content teachers proposed vocabulary and content questions while the language teachers designed communicative, group writing activities, listening and oral tasks, as well as some grammar revision exercises based on the structures that appeared in the texts. All the units included similar sections and their tasks were topic centred. 
The materials were published in a private web-based platform, PoliformaT, held on the university web site and which is a development of Sakai CLE. Sakai CLE is a free and open source Courseware Management System, featuring a set of software tools designed to help instructors, researchers and students collaborate online in support of their work--whether it be course instruction, research or general project collaboration. For coursework, Sakai provides features to supplement and enhance teaching and learning. For collaboration, Sakai has tools to help organize communication and collaborative work on campus and around the world. Thus, students were able to complete the tasks and send their answers to the teachers using this platform. In turn, teachers could send files or communicate with students in a flexible and interactive way.

Finally, the materials were trialled in the first semester of the academic year with a pilot group of forty students enrolled in the first year of the Industrial Engineering degree course. The pilot group was further sub-divided into groups of three. Intergroup collaboration through e-mail, the subject forum and chats was encouraged.

The second part of the project consisted of evaluating the materials using the student and teacher feedback and, based on these suggestions, modifying the materials where necessary. We also contrasted the results of the evaluation of the pilot material with the results of the evaluation of the previous year's materials - which consisted of a printed textbook with no collaborative or online activities, although it did include materials based on the communicative approach.

The evaluation process was carried out in three phases: teacher evaluation; peer evaluation (of each group member) and self-evaluation. Teachers focused on the clarity of the guidelines and instructions, on the appropriateness and effectiveness of the tasks, and on the level of language and the background knowledge required to carry them out.

For each assignment, students were not given individual marks but received a group grade. This was to foment collaboration. Its purpose was to encourage attendance and participation as well as subject matter and language acquisition.

Peer evaluation was performed anonymously and focused more on the exercises that involved oral presentations or discussion tasks. Students were asked to grade individually (i) the language learning of their team members, (ii) the subject matter learning of their team members, (iii) the contribution of each person to the collaborative process.

Self-evaluation was carried out by everyone involved; that is, language teachers, content teachers and students. In addition, each person was asked to write a report on one of the teaching units (on one of the thirty topics). Self-evaluation included questions about subject matter content, collaborative activities and processes, and second language acquisition tasks. As a result of the evaluation process, the materials were updated regularly at the beginning and at the end of each semester in order to adapt them to the students' needs. At the end of the academic year, content and language teachers met in order to agree on any further changes it was felt should be made to the materials for the upcoming academic year.

Finally, students completed the standard university course satisfaction questionnaire. Analysis of the responses showed that when compared with previous years student satisfaction had increased by $30 \%$ for both content and language subjects. In addition, when we compared the marks obtained in content and language subjects, we found that for both the number of 
students obtaining a pass had increased by $20 \%$.

\section{Results}

Some examples of the material designed can be seen in this section. As explained above, each unit followed the same format: introduction; objectives; online tasks; follow up and vocabulary. Below it can be observed an example of the introduction to one of the topics, in this case, protection of the environment. The example 1 is based on one of the websites used:

Websites: http://www.epa.gov/epahome/students.htm; http://www.epa.gov/students

Pollution is a very important and negative effect of industrial progress and development. All industrial activities may have harmful consequences on our environment. On the other hand, environmental consciousness is becoming a matter of prime importance both for the society as a whole and for the industrial world. Consequently, the Industrial Engineer should be aware of the negative impact of his/her activity on the environment, and know how to minimize this impact.

Example 1: Introduction.

Example 2 shows how the objectives were explained and the outcomes the students could expect:

The tasks in this unit are intended to give you the opportunity to learn more about environmental and pollution related issues of interest for your professional career as an engineer. You can learn relevant vocabulary and, to a lesser extent, grammar, within an authentic context. Apart from the corresponding vocabulary, you will practice all major skills in this context: reading, writing, and also speaking and listening. You will learn to build glossaries, interpret authentic online information, and use this information to carry out problem solving and simulation activities. You will be able to practice technical writing skills (describing changes and processes and report-writing) and to share information with a partner.

Example 2: Aims and objectives.

In the third part of the unit, we included different online activities to encourage comprehension and the acquisition of vocabulary. Examples 3 to 6 show some activities designed to improve reading comprehension and vocabulary, grammar, writing, speaking and listening. Although the exercises in these examples are based on a website aimed at children, its accessibility makes it a useful resource. Students considered this kind of web sites appropriate for their needs and knowledge as this site was chosen by the students themselves. 


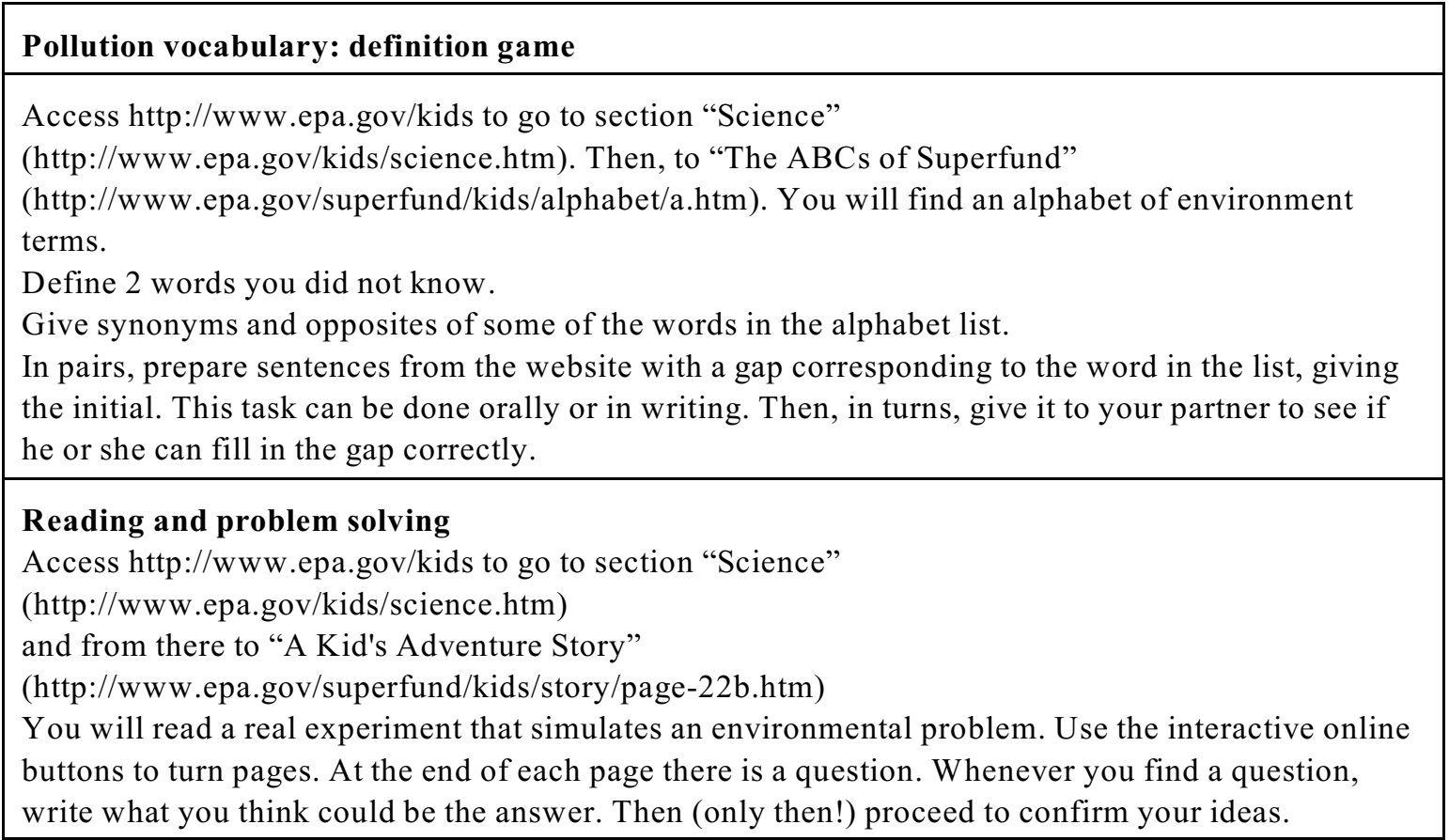

Example 3: Online tasks: Reading comprehension and vocabulary.

\section{Writing a company pollution report \\ Grammar practice in context}

From http://www.epa.gov/kids/game.htm you must go to "What's Wrong with this Picture?" (http://www.epa.gov/OWOW/NPS/kids/whatwrng.htm). Follow the instructions to carry out this online task, and you will learn how to correct some daily habits that are environmentally dangerous. Before you start, be ready and alert to notice the verb forms you will encounter while you do the online game.

a) In which verbal form are the verbs of the big sentences in red? Why?

b) With information from the activity, write several rules you can follow to prevent these dangerous habits. You must use modal verbs (for example: mustn't, should, have to, etc.).

Example 4: Online tasks: Grammar activities.

\footnotetext{
Writing a company pollution report

You can work individually or in small groups. Imagine you work for an industrial company. Your boss wants you to report on the types of pollution and waste produced by your company.

Considering the characteristics and activities of the company, you should write a short report (it can be a text or an organized list) about the types of pollution and waste relevant to your company. To make your report complete, please include a brief overview of the company (name and activity) at the beginning, and comments (or recommendations) about how to prevent pollution in your company at the end. Be concise and realistic!

To find useful information, access http:/www.epa.gov/students/waste.htm, then go to "Superfund:

Hazardous Substance and Hazardous Waste" (at http://www.epa.gov/superfund/students/clas _act/index.htm), and finally to section "Waste Site Activity"

(http://www.epa.gov/superfund/students/wastsite/index.htm).
}

Example 5: Writing activities. 


\section{Speaking to share information}

Choose one of the following speaking tasks. Work in pairs.

a) Alternative 1: "Water Pollution"

From http://www.epa.gov/students/water.htm enter "Cleanup for Kids"

(http://response.restoration.noaa.gov/kids/kids.html)

and then go to "Answers to your questions"

(http://response.restoration.noaa.gov/faqs/faq.html)

In pairs, take turns to ask and answer 4 questions orally.

b) Alternative 2: "Environmental terms"

From http://www.epa.gov/students/basics.htm enter "Terms of environment"

(http://www.epa.gov/OCEP Aterms).

In pairs, take turns to ask and answer 4 questions orally about the meaning of environmental words.

\section{Watching a video}

Access http://www.epa.gov/students/conserva.htm and then go to "Ozone Depletion" at http://www.epa.gov/ozone/science. Then enter "Forecast Earth"

(http://www.epa.gov/ozone/science/ movies/index.html), where you can play videos on environmental issues, together with a full written transcript. Watch one video and write a glossary of key words (include the pronunciation and definition or translation of the words). Now you can practice the pronunciation of the words in your glossary.

Example 6: Speaking and listening activities.

In the fourth part of the unit, a follow up section (see example 7) suggested further language and content tasks:

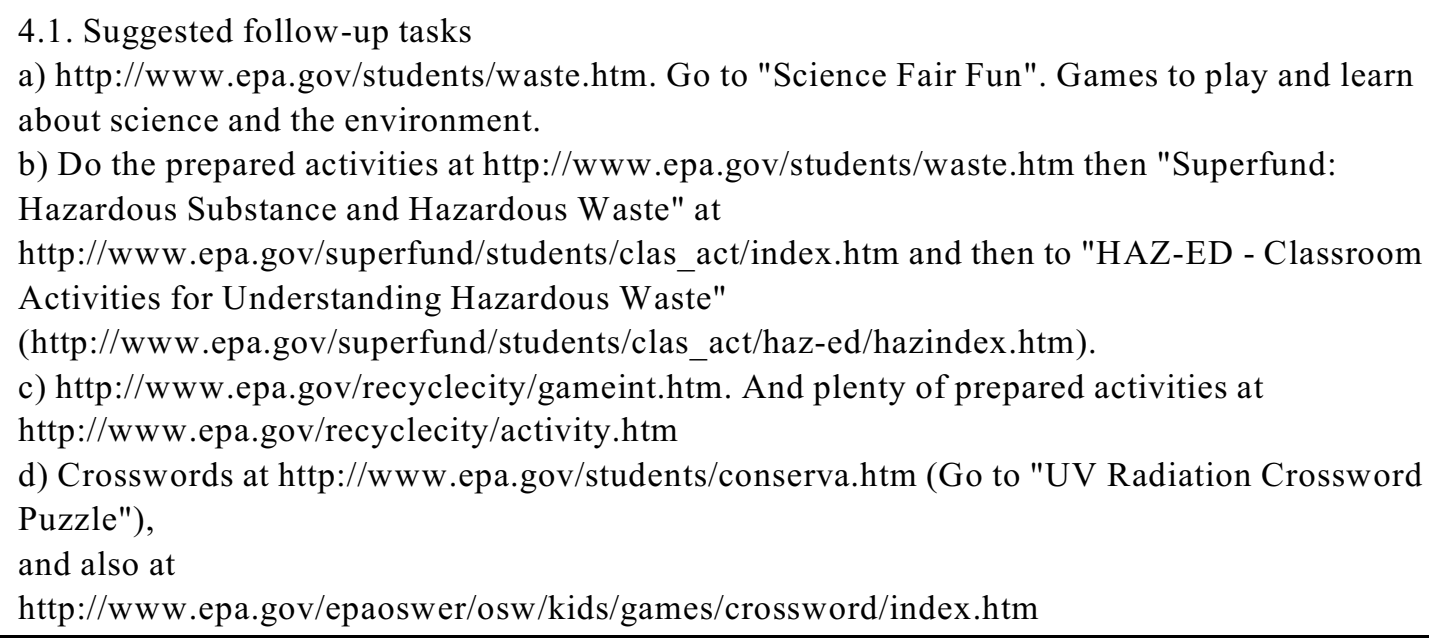

Example 7: Follow up section.

The fifth and final part (see Example 8: Glossary) was devoted to explaining some of the key words of the activities in order to highlight the main ideas of the unit: 


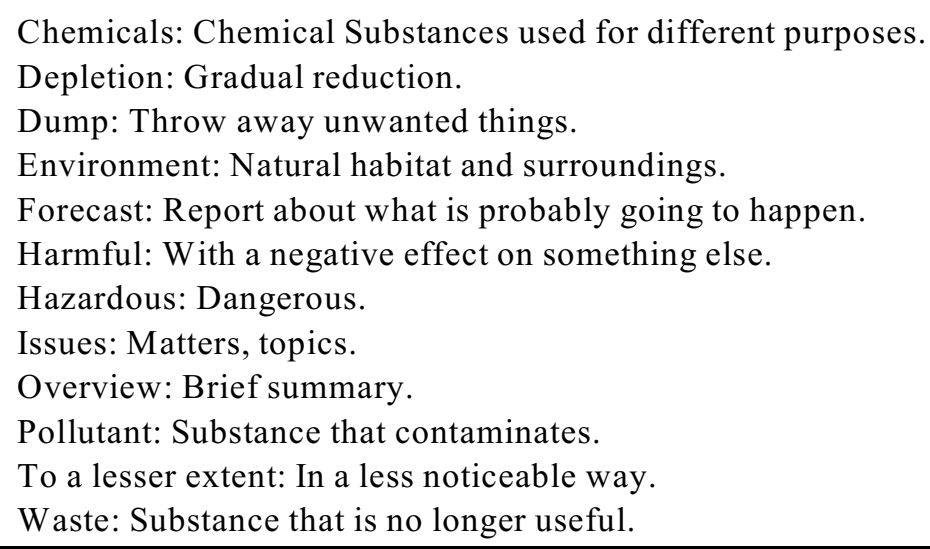

Example 8: Glossary.

After evaluating the process of material design and analysing the results obtained, we considered that the factors which most contributed to success were that the teachers involved in the project were reasonably competent users of the technology, that specific class time was allocated for the students to use computers, and that the teachers involved favoured a studentcentred approach to pedagogy as well as collaborative projects which were partly defined by students' interest. Furthermore, the students were aware that the materials were based on the subject syllabus and on the language syllabus and were highly motivated.

\section{Conclusions}

The blended approach we explain in this article is a novelty we wish to introduce in material design. Additionally, the content and language integrated learning approach we suggest here is different from the approach explained by, for example, Frigols, Marsh and Naysmith (2007: 33). We promote a much closer collaboration between the content teacher and the language teacher. Furthermore, both the materials and the classes are balanced between content and language tasks although the teachers do not teach together in class. This is why our proposal, although based on CLIL, is different.

A further point to make is that second language learning should be integrated in everyday activities and seen as part of the students' environment. Students should come to regard language as a practical tool used to communicate with people all around the world. When this communicative aspect is forgotten the practice of a second language can become restricted to sterile gap filling and other drills. We believe that in the information era, teachers need to adapt their materials and methodologies to better reflect the needs of students and to make use of the possibilities available.

In our study we observed that students preferred online activities to traditional ones, perhaps because they found the dynamic characteristics of the tasks more stimulating. After using online materials with our students for four years, we have noticed that online activities have resulted in greater understanding and in improved writing and speaking of the students. Self-esteem has been reinforced and other skills such as searching for information, learning 
independence, resourcefulness, etc. have also been developed. Students feel more confident about using a second language after the online activities which, in a sense, force them to engage with the language and to continually evaluate what they need to do.

In conclusion, we can state that new teaching approaches should be implemented to teach a second language, for example, CLIL and CA, and a dynamic tool such as the Internet should be used as a vehicle. Higher education students are now used to technology and demand updated materials; as a consequence, teachers should take advantage of online materials and communication tools. In this article we have highlighted the process followed in order to design material based on web sites. The benefits of designing teaching-learning materials in this way can be summed up as follows:

- The integration of the content teacher and the language teacher to design the material, taking into account the needs of students and the possibilities of using authentic technical texts;

- The development of collaborative work, students have to plan their learning material with teachers and colleagues;

- It stimulates interpersonal communication through group activities;

- It is challenging and motivating, students are required to learn content and language;

- The incorporation of technology allows contributions of different kinds from students as well as providing them with different forms of learning.

\section{Notes}

1. The Common European Framework provides a common basis for the elaboration of language syllabuses, curriculum guidelines, examinations, textbooks, etc. across Europe. More information at $<$ www.uk.cambridge.org/elt $>$.

\section{References}

Burns, A. (1999): Collaborative Action Research for English Language Teachers. Cambridge: Cambridge University Press.

Carrió Pastor, María Luisa (ed.) (2006): Aprendizaje colaborativo asistido por ordenador. Valencia: Blau Verd.

. (2009a): "Enhancing learner-teacher collaboration through the use of on-line activities". In

I. González-Pueyo; C. Foz-Gil; M. Jaime Siso and M. J. Luzón Marco, eds., Teaching Academic and Professional English Online. Berlin: Peter Lang. . (ed.) (2009b): Content and Language Integrated Learning: Cultural Diversity. Berlin: Peter Lang.

Carrió Pastor, María Luisa and Ana Gimeno Sanz (2007): "Content and language integrated learning in a technical higher education environment". In D. Marsh and D. Wolff, eds., Diverse contextsconverging goals. Berlin: Peter Lang.

Chapelle, Carol A. (2001): Computer applications in second language acquisition: Foundations for teaching, testing, and research. Cambridge: Cambridge University Press. 
. (2003): English language learning and technology. Amsterdam: John Benjamins.

. (2004): "Technology and second language learning: expanding methods and agendas". System 32: 593-601.

Coyle, Do (2009): "Promoting cultural diversity through intercultural understanding: a case study of CLIL teacher professional development at in-service and pre-service levels". In M. L. Carrió Pastor, ed., Content and Language Integrated Learning: Cultural Diversity. Berlin: Peter Lang. . (2007): "The CLIL quality challenge". In D. Marsh and D. Wolff, eds., Diverse ContextsConverging Goals. Berlin: Peter Lang.

Ezeiza Ramos, Joseba (2009): "Integrating languages, contents and cultures in the European Space for Higher Education: from theory to practice". In M. L. Carrió Pastor (ed.) Content and Language Integrated Learning: Cultural Diversity. Berlin: Peter Lang.

Frigols, María José; David Marsh and John Naysmith (2007): "Competence-building for teachers of CLIL: vocational education". In D. Marsh and D. Wolf, eds., Diverse contexts-converging goals. Bern: Peter Lang.

González Fernández, R. (2006): "Las estrategias y técnicas didácticas en el rediseño". $<\mathrm{http}$ ://www.sistema.itsm.mx/va/dide/inf-doc/estrategias/colaborativo.html $>$ (15/01/2006).

Hodgson, Isabel \& S. R. Jones (2009): "Working across boundaries with CLIL". In M. L. Carrió Pastor, ed., Content and Language Integrated Learning: Cultural Diversity. Berlin: Peter Lang.

Imus, A., R. Ployhart, D. Ritzer \& M. Sleigh (2004): “An understanding of students' perceptions of technology use in the classroom". Inventio: Creative Thinking about Learning and Teaching $6(1)$.

Lea, L.; M. Clayton, B. Draude \& S. Barlow (2001): "The impact of technology on teaching and learning”. Educause Quarterly 2(1): 69-71.

Li, J. (2006): "The mediation of technology in ESL writing and its implications for writing assessment". Assessing Writing 11:5-21.

Luke, C. (2006): "CALL in the broader context". In L. Ducate \& N. Arnold, eds., Calling on CALL: From Theory and Research to New Directions in Foreign Language Teaching. San Marcos, Texas: CALICO, 21-41.

Marsh, David (2009): "Introduction: culture, education \& content and language integrated learning". In M. L. Carrió Pastor, ed., Content and Language Integrated Learning: Cultural Diversity. Berlin: Peter Lang.

McCafferty, S. G; G. M. Jacobs and A. C. DaSilva Iddings (2006): Cooperative Learning and Second Language Teaching. Cambridge: Cambridge University Press.

Morton, Tom (2009): "Integrating language and content in secondary CLIL History: the potential of a genre-based approach". In M. L. Carrió Pastor, ed., Content and Language Integrated Learning: Cultural Diversity. Berlin: Peter Lang.

Nunan, David (1991): Language Teaching Methodology. Hemel Hempstead: Prentice Hall.

Richards, C. (2005): "The design of effective ICT-supported learning activities: exemplary models, changing requirements, and new possibilities". Language Learning and Technology 9(1): 60-79.

Roschelle, J. \& S. D. Teasley (1995): "Construction of shared knowledge in collaborative problem-solving”. In C. O’Malley, ed., Computer Supported Collaborative Learning. Berlin: Springer-Verlag: 69-97.

Schrodt, P. \& P. Turman (2005): "The impact of instructional technology use, course design, and sex differences on students' initial perceptions of instructor credibility". Communication Quarterly 53(2): 177-196. 
Soetaert, R. \& B. Bonamie (2006): "New rules for the language \& content game”. From CBLT/CALL to CLIL/TILL. <www.euroclic.net/index> (15/01/2006).

Spodark, E. (2005): "Technoconstructivism for the undergraduate foreign language classroom". Foreign Language Annals 38(3): 428-435.

Strijbos, J.; R. L. Martens and W. M. G. Jochems (2004): "Designing for interaction: Six steps to designing computer-supported group-based learning". Computers \& Education 42: 403-424.

Taylor, R. and C. Hitsaki (2004): "Teaching WELL and loving IT". In S. Fotos and C. M. Browne, eds., New perspectives on CALL for second language classrooms. New Jersey: Lawrence Erlbaum: 131-148.

Wolf, Dieter (2007): "CLIL: bridging the gap between school and working life". In D. Marsh and D. Wolf, eds., Diverse contexts-converging goals. Bern: Peter Lang. 